\title{
Relationship between Soil Characteristics and Stand Structure of Robinia pseudoacacia L. and Pinus tabulaeformis Carr. Mixed Plantations in the Caijiachuan Watershed: An Application of Structural Equation Modeling
}

\author{
Xi Wei ${ }^{1}$, Huaxing Bi ${ }^{1,2,3,4, *}$, Wenjun Liang ${ }^{5}$, Guirong Hou ${ }^{1}$, Lingxiao Kong ${ }^{1}$ and \\ Qiaozhi Zhou ${ }^{1}$ \\ 1 School of Soil and Water Conservation, Beijing Forestry University, Beijing 100083, China; \\ weixi860826@163.com (X.W.); hgralex@163.com (G.H.); konglx958 @163.com (L.K.); \\ Gracezqz@163.com (Q.Z.) \\ 2 Beijing Collaborative Innovation Center for Eco-Environmental Improvement with Forestry and Fruit Trees, \\ Beijing 102206, China \\ 3 Ji County Station, Chinese National Ecosystem Research Network (CNERN), Beijing 100083, China \\ 4 Beijing Forestry University, Key Laboratory of State Forestry Administration on Soil and Water \\ Conservation, Beijing 100083, China \\ 5 College of Forestry, Shanxi Agricultural University, Taigu 030801, China; liangwenjun123@163.com \\ * Correspondence: bhx@bjfu.edu.cn; Tel.: +86-10-6233-6756
}

Received: 20 December 2017; Accepted: 3 March 2018; Published: 6 March 2018

\begin{abstract}
In order to study the multi-factor coupling relationships between typical Robinia pseudoacacia L. and Pinus tabulaeformis Carr. mixed plantations in the Caijiachuan basin of the Loess Plateau of Shanxi Province, West China, 136 sample plots were selected for building a structural equation model (SEM) of three potential variables: terrain, stand structure, and soil characteristics. Additionally, the indicators (also known as observed variables) were studied in this paper, including slope, altitude, diameter at breast height (DBH), tree height $(\mathrm{TH})$, tree crown area, canopy density, stand density, leaf area index (LAI), soil moisture content, soil maximum water holding capacity (WHC), soil organic matter (SOM), total nitrogen (TN), total phosphorus (TP), ammonia-nitrogen $\left(\mathrm{NH}_{3}-\mathrm{N}\right)$, nitrate-nitrogen $\left(\mathrm{NO}_{3}-\mathrm{N}\right)$, and available phosphorus (AP). The results showed that terrain was the most important factor influencing soil moisture and nutrients, with a total impact coefficient of 1.303 and a direct path coefficient of 0.03 , which represented mainly positive impacts; while correspondingly stand structure had a smaller negative impact on soil characteristics, with a total impact coefficient of -0.585 and a direct path coefficient of -0.01 . The terrain also had a positive impact on the stand structure, with a total impact coefficient of 0.487 and a direct path coefficient of 0.63 , indicating that the topography factors were more suitable for site conditions and both the stand structure and the soil moisture and nutrient conditions were relatively superior. By affecting the stand structure, terrain could restrict some soil, water, and nutrient functions of soil and water conservation. The influence coefficients of the four observed variables of DBH, stand density, soil water content, and organic matter, and potential variable topography reached $0.686,-0.119,1.117$, and 0.732 , respectively; and the influence coefficients of soil moisture, organic matter and stand structure were -0.502 and -0.329 , respectively. Therefore, besides observing the corresponding latent variables, the observed variables had a considerable indirect influence on other related latent variables. These relationships showed that the measures, such as changing micro-topography and adjusting stand density, should effectively maintain or enhance soil moisture and nutrient content so as to achieve improved soil and water conservation benefits in the ecologically important Loess Area.
\end{abstract}


Keywords: structural equation model; Robinia pseudoacacia L. and Pinus tabulaeformis Carr. mixed plantations; stand structure; soil characteristics; soil and water conservation function

\section{Introduction}

Large-scale afforestation in the Western Shanxi Loess Area started in the early 1990s, and the area has been covered by larger-sized plantations over the past 20 years. Mixed afforestation methods-with plantations consisting of two or more tree species—are often used. In the mixed plantations, tree species other than the main tree species represent over $20 \%$ of the plantation, in terms of number of trees, cross-sectional area, or volume. The impact of vegetation construction on soil and water resources has also aroused great attention, both at home and abroad, particularly in the Loess Plateau-an area known for soil and water loss, a lack of water resources, a fragile ecological environment, and a lack of a strong conservation ethics. The main reasons for the creation of large-scale plantations in this region, and their impacts on soil and water conservation, water resources security, and regional sustainable development, have been a particular cause for concern. The relationships between the stand structures of the plantations and soil and water conservation have also gradually become the foci of academic research.

Many studies on the stand structure and soil and water conservation functions of the Loess Plateau, as well as other ecologically sensitive areas, have been carried out, usually aimed at one, or several, dimensions. For example, Bi Huaxing et al. utilized the principle of water balance to establish a suitable coverage calculation model based on spatial and temporal differentiation of soil moisture and water consumption [1]; Brzostek et al. proposed that chronic water stress could reduce the tree growth of forests, and also considered the extent to which forests ameliorate climate warming [2]; and Panagos et al. presented an assessment of soil loss due to water erosion in Europe, and also suggested some policy measures that should be targeted [3]. Other scholars have also presented research results on some factors related to the stand structure, soil moisture [4,5], and soil nutrients [6] in the Loess Plateau. However, research on the multi-factor coupling relationships between stand structure and soil moisture and nutrients [7] is relatively lacking. Traditionally, the main functions of water and soil conservation in gully areas of this type are regarded as water resource conservation and erosion reduction [8]. Water conservation has manifested as soil water storage capacity and soil conservation often incorporates the preservation, storage, recycling, conversion, and acquisition of soil organic matter, nitrogen, phosphorus, and other nutrients [9].

Structural equation modeling (SEM) has become increasingly precise and is now widely used in ecological studies [10-13], mainly for the purpose of quantifying the relationships between multiple factors. Essentially, SEM aims to generate strong and distinct links between theoretical and experimental ideas [14]. The ability to disentangle causal relationships and to test competing models and theories (as opposed to null hypotheses) are key strengths of SEM methods [15]. Due to their statistical strength and applicability, SEM approaches have been employed in a wide range of environmental and ecological studies [16-19]. For example, SEM has been applied to evaluate the effect of grazing on ecosystem processes [20,21]; the relationships between fire and edaphic factors and woody vegetation structure and composition [22]; the sensitivity of soil respiration to environmental factors [23]; the impacts of land uses on stream integrity [24]; the factors that affect plant richness in recovering forests $[25,26]$; the relationships associated with the decline in species richness, as natural landscapes undergo conversion to human-dominated landscapes [27]; and both the direct and indirect association of plant species richness to landscape conditions and local environmental factors [28,29]. However, to our knowledge, SEM methods have not been applied to study stand structure impacts on soil and water conservation.

In this paper, the covariance SEM is used to quantify the multi-factor coupling relationship between soil moisture and nutrients in typical plantations. Soil moisture content and soil maximum 
water holding capacity are taken as water conservation indicators, and organic matter, nitrogen, and phosphorus are used as conservation soil indicators. These indicators are all used to study soil characteristics and their relationships with the topography and stand structure in order to reveal the role of stand structure on the conservation of water sources and soil function mechanisms, and to further provide references of control technology regarding the practical and suitable slope stand structural adjustments in the Loess Plateau.

\section{Materials and Methods}

\subsection{Site Description}

The Caijiachuan Watershed served as the study site; it is located on the Loess Plateau in Ji County, Shanxi Province, China $\left(35^{\circ} 53^{\prime}-36^{\circ} 21^{\prime} \mathrm{N}, 110^{\circ} 27^{\prime}-111^{\circ} 7^{\prime} \mathrm{E}\right.$; elevation $\left.904-1592 \mathrm{~m}\right)$, and is a typical gully area. Meteorological records indicate that the long-term mean annual air temperature is $10.2^{\circ} \mathrm{C}$ and the frost-free period is 172 days. The average annual precipitation is $571 \mathrm{~mm}$, with an uneven distribution. The average annual potential evapotranspiration (PET) is $1724 \mathrm{~mm}$, which far exceeds the rainfall. Inside this area, the type of soil is mainly Haplic Luvisols (Soil classification of the Food and Agriculture Organization of the United Nations) and is mostly alkaline. There are mainly artificial shelterbelts of black locust (Robinia pseudoacacia L.) and Chinese pine (Pinus tabulaeformis Carr.) in the nested watershed, with an area of $38 \mathrm{~km}^{2}$ and a forest cover rate of $72 \%$. The main shrubs under the forests are periploca (Periploca sepium Bunge), yellow rose (Rosa xanthine Lindl.), sophora viciifolia (Sophora davidii (Franch.) Skeels), meadowsweet (Spiraea salicifolia L.), lilac (Syringa linn.), elaeagnus umbellata (Elaeagnus pungens Thunb.), etc. Through the investigation of forestland, shrubland, and grassland in this area, dominant species of artificial R. pseudoacacia and P. tabulaeformis forests with different slopes, aspects, and altitudes were selected as objects and studied.

\subsection{Data Acquisition and Processing Methods}

Thirty-four standard plots of $20 \mathrm{~m} \times 20 \mathrm{~m}$ were set up at the plantations and 136 sample plots of $10 \mathrm{~m} \times 10 \mathrm{~m}$ were set up with shady, semi-shady, sunny, and semi-sunny aspects (one standard plot was divided into four equal sample plots to reduce the heterogeneity) The slopes of the plots ranged from $15^{\circ}$ to $45^{\circ}$, and were distributed at an average elevation of $1133.5 \mathrm{~m}$ above sea level (Table 1). The mixture of plantation species consisted of R. pseudoacacia and P. tabulaeformis at a ratio of 8:2, as $R$. pseudoacacia was the dominant species. Using individual field measurements in these plots, the varieties of trees, diameter at breast height (DBH), tree height $(\mathrm{TH})$, and tree crown area were measured, and then the canopy density and stand density were calculated. The leaf area indices of the quadrats were determined using a LAI-2000 (LI-COR Company, Lincoln, NE, USA) vegetation canopy analyzer. According to the trophic classification scheme for functions of soil and water conservation [8], indicators of water resources and soil protection were confirmed. Mixed soil samples, 0-60 cm, were collected using the cutting ring method and were representative of forest soils in this area; soil moisture content was determined using the drying method; and water holding capacity (WHC) was measured using the soil infiltration method [30]. After air-dried soil was sieved (0.15 mm sieve), indoor experiments were conducted. The contents of soil organic matter (SOM), total nitrogen (TN), total phosphorus (TP), ammonia-nitrogen $\left(\mathrm{NH}_{3}-\mathrm{N}\right)$, nitrate-nitrogen $\left(\mathrm{NO}_{3}-\mathrm{N}\right)$, and available phosphorus (AP) were measured with a SmartChem-200 (AMS/Alliance Instruments, Paris, France) discrete wet chemistry analyzer. The major geographical and biological characteristics of the investigated plots are summarized in Table 2. 
Table 1. The distribution of aspects, slopes, and altitudes of the sample plots in the Caijiachuan Watershed.

\begin{tabular}{|c|c|c|c|c|c|c|}
\hline Aspect & \multicolumn{2}{|c|}{ Shady } & Semi-Shady & \multicolumn{2}{|c|}{ Sunny } & Semi-Sunny \\
\hline Sample quantity & \multicolumn{2}{|c|}{7} & 11 & \multicolumn{2}{|c|}{6} & 10 \\
\hline Slope $/^{\circ}$ & \multicolumn{2}{|c|}{$\leq 15$} & $16-25$ & \multicolumn{2}{|c|}{$26-35$} & $\geq 36$ \\
\hline Sample quantity & \multicolumn{2}{|c|}{2} & 15 & \multicolumn{2}{|c|}{15} & 2 \\
\hline Altitude/m & $900-1000$ & $1000-1100$ & $1100-1150$ & $1150-1200$ & $1200-1300$ & $>1300$ \\
\hline Sample quantity & 2 & 6 & 15 & 8 & 3 & 0 \\
\hline
\end{tabular}

Notes: (1) The distribution of aspect tends to be mostly homogeneous. (2) The lands featuring gentle slopes $(\leq 15)$ are usually cropland and those that are dangerously steep $(\geq 36)$ are difficult sites to access, as such, there are very few of either type of these sites for afforestation, whereas many sites with deep slopes (16-35) are used for afforestation in order to restore vegetation and improve the environment in China. (3) In the watershed, low-altitude (900-1000 $\mathrm{m}$ ) areas are mainly agricultural lands or areas where people are living, so there are very few low-altitude sites for afforestation; high-altitude $(>1300 \mathrm{~m})$ areas are mainly distributed with natural forests, so there are no high-altitude plantations; the mid-altitude areas (1000-1300 m) are the main afforestation areas of mixed plantations, and can therefore be regarded as being representative of the mixed plantations in the region.

Table 2. The survey of the species of Robinia pseudoacacia L. and Pinus tabulaeformis Carr. mixed plantations in the Caijiachuan Watershed, Shanxi Province, West China. DBH, diameter at breast height; LAI, leaf area index; WHC, water holding capacity; SOM, soil organic matter; TN, total nitrogen; TP, total phosphorus; NH3-N, ammonia-nitrogen; NO3-N, nitrate-nitrogen; AP, available phosphorus.

\begin{tabular}{cccc}
\hline Stands and Soil Characteristics & Maximum & Minimum & Average \\
\hline Slope $\left(^{\circ}\right)$ & 45 & 15 & 26.50 \\
Altitude $(\mathrm{m})$ & 1220 & 960 & 1133.53 \\
DBH $(\mathrm{cm})$ & 18.54 & 6.37 & 10.85 \\
Tree height $(\mathrm{m})$ & 13.4 & 3.0 & 8.2 \\
Crown area $\left(\mathrm{m}^{2}\right)$ & 16.74 & 2.80 & 8.12 \\
Canopy density & 0.88 & 0.38 & 0.64 \\
Stand density (trees·hectare $\left.{ }^{-1}\right)$ & 4400 & 500 & 1679 \\
LAI & 4.50 & 0.88 & 2.06 \\
Soil moisture content $(\%)$ & 40.03 & 5.66 & 13.71 \\
$\mathrm{WHC}(\%)$ & 122.88 & 25.54 & 50.41 \\
$\mathrm{SOM}\left(\mathrm{g} \cdot \mathrm{kg}^{-1}\right)$ & 122.55 & 1.31 & 16.08 \\
$\mathrm{TN}\left(\mathrm{g} \cdot \mathrm{kg}^{-1}\right)$ & 4.65 & 0.01 & 0.69 \\
$\mathrm{TP}\left(\mathrm{g} \cdot \mathrm{kg}^{-1}\right)$ & 7.60 & 0.03 & 0.66 \\
$\mathrm{NH}_{3}-\mathrm{N}\left(\mathrm{mg}^{-1} \mathrm{~kg}^{-1}\right)$ & 66.84 & 2.79 & 20.99 \\
$\mathrm{NO}_{3}-\mathrm{N}\left(\mathrm{mg}^{-1} \mathrm{~kg}^{-1}\right)$ & 88.40 & 0.12 & 10.27 \\
$\mathrm{AP}\left(\mathrm{mg}^{-1} \mathrm{~kg}^{-1}\right)$ & 117.64 & 0.16 & 36.00 \\
\hline
\end{tabular}

\subsection{Structural Equation Modeling}

SEMs (also known as path analyses) are statistical multivariate models that are used to estimate causality and direct or indirect relationships between multiple variables [31]. These models are less restrictive than regression models in that some variables may play the role of predictor variable and dependent variable simultaneously [32,33]. SEM starts by constructing an a priori schema: an analytical model that represents all hypothetical causal links between the predictors and the response variables, based on previous knowledge of the ecological system [34].

Thus, SEM in ecology is a method to test ecosystem structure and function [35], which is closely related to (and is actually a more general form of) several types of statistical analyses, including regression, principal components analysis (PCA), and path analysis [36]. Furthermore, it can explore the relationships between observed variables, latent variables, and residuals to quantitatively describe the influence of independent variables on dependent variables, including direct, indirect, and total impacts [13]. However, in contrast to some other methods, SEM provides a means to evaluate both the structure of the model as well as a specific parameterization of the model structure using data [37]. 
By "model structure", we mean the pattern of relationships among variables (correlations, direct, and indirect relationships among variables). The structural equation model includes two parts of the measurement model and the structural model; the formula is as follows [38-40]:

$$
\begin{gathered}
X=\Lambda x \xi+\delta \\
Y=\Lambda y \eta+\varepsilon \\
\eta=\eta+\Gamma \xi+\zeta
\end{gathered}
$$

Equations (1) and (2) are measurement models, used to describe the relationship between latent and observed variables, where $X$ is the exogenous observation variable vector, $Y$ is the endogenous observation variable vector, $\Lambda x$ and $\Lambda y$ are the factor loadings of the indicator variables $(X, Y), \delta$ and $\varepsilon$ are the measurements of the exogenous observation variables and the endogenous observation variables, $\xi$ is the exogenous latent variable, and $\eta$ is the endogenous latent variable.

Equation (3) is a structural model that can reflect the relationships between the potential variables, where is the structural coefficient matrix of the relationship between endogenous latent variables, $\Gamma$ is the structural coefficient matrix of the relationships between endogenous latent variables and exogenous latent variables, and $\zeta$ is the interference factor or residual value of the structural model. The initial model with the aid of a path map reflects the relationships among the variables in the structural model, and the path coefficients represent the extent of the relationship between the variables. After the path diagram is established, the path coefficients of all the paths are usually calculated using the maximum likelihood method [13], which is also used in this study.

The climate, hydrology, and other environmental conditions in the area were basically the same, and the different topographical factors $\left(\xi_{1}\right)$ were used as potential exogenous variables. The slope, aspect, slope position, and altitude were taken into account in the modeling. In consideration of the aspect and slope position being subject to qualitative description and random selection in the survey, the slope $\left(x_{1}\right)$ and elevation $\left(x_{2}\right)$ were determined to be the index of the initial model belonging to the exogenous observation variables, because they are the indicators of accurate measurement. Their corresponding errors are $\delta_{1}$ and $\delta_{2}$, respectively.

The differences between quadrats were also reflected in the stand structure $\left(\xi_{2}\right)$. The measuring indices affecting the stand structure mainly included DBH $\left(x_{3}\right)$, TH $\left(x_{4}\right)$, tree crown area $\left(x_{5}\right)$, canopy density $\left(x_{6}\right)$, stand density $\left(x_{7}\right)$, and LAI $\left(x_{8}\right)$, which were also exogenous observation variables as well. The corresponding errors were $\delta_{3}, \delta_{4}, \delta_{5}, \delta_{6}, \delta_{7}$, and $\delta_{8}$. Soil properties $(\eta)$ were taken as potential endogenous variables, and their corresponding indices, such as soil moisture content $\left(y_{1}\right)$, WHC $\left(y_{2}\right)$, $\operatorname{SOM}\left(y_{3}\right), \mathrm{TN}\left(y_{4}\right), \mathrm{TP}\left(y_{5}\right), \mathrm{NH}_{3}-\mathrm{N}\left(y_{6}\right), \mathrm{NO}_{3}-\mathrm{N}\left(y_{7}\right)$, and AP $\left(y_{8}\right)$, were determined as endogenous observation variables, of which the corresponding errors were $\varepsilon_{1}, \varepsilon_{2}, \varepsilon_{3}, \varepsilon_{4}, \varepsilon_{5}, \varepsilon_{6}, \varepsilon_{7}$, and $\varepsilon_{8}$. In addition, the modeling process needed to consider the residuals of three potential variables as $\zeta_{1}, \zeta_{2}$, and $\zeta_{3}$.

After creating an initial model based on previous knowledge, site information, and background data, a chi-square value $\left(\chi^{2}\right)$ test was then conducted to examine whether the covariance structure suggested by the model satisfactorily fits the covariance structures [19]. The $\chi^{2}$, degree of freedom $(d f$, $\left.0 \leq \chi^{2} / d f \leq 3\right)$, probability level $(p>0.05)$, root mean square error of approximation $(0 \leq$ root meant square error of approximation (RMSEA) $\leq 0.05)$ [40], and comparative fit index ( $0.9 \leq$ comparative fit index $(\mathrm{CFI}) \leq 1.00)$ were given to determine the "best" model that has the highest predictive performance, while the comparative fit index $(0.7 \leq \mathrm{CFI} \leq 0.90)$ was "tolerable" [41]. If the parameters exhibit beyond the proper range after model running the model, we should use two methods for model correction: "modification index" and "critical ratio (CR) for difference", provided by the Amos 22.0 software (IBM/International Business Machines Corporation, Armonk, NY, USA) package. In the model diagram, the double arrow ("<->") section was the covariance correction index between the residual variables, and the single arrow (" $\rightarrow$ ") section was a regression weight correction index between variables, indicating that if an arrow is added between two variables, at least the chi-squared value of the model will be reduced. In addition, the CR statistic followed a normal distribution, 
so its value can be used to judge whether there is a significant difference between the two estimated parameters. In this study, the former method was selected to modify the model, according to the characteristics of the investigated measurable variables.

\section{Results}

\subsection{Model Construction and Correction}

SEM has been shown to be verifiable, therefore, the basis for the study of the coupling relationships between stand structure and soil properties was taken into consideration when building the model. The data in this research conformed to a multivariate normal distribution, and maximum likelihood estimation was used to quantitatively analyze potential and observed variables. SPSS 19.0 software (IBM/International Business Machines Corporation, Armonk, NY, USA) was used for data exploratory analysis. Using Amos 22.0 software (IBM/International Business Machines Corporation, Armonk, NY, USA) for drawing the path map and parameter estimation, the path coefficient between each variable, the factor load of each variable, the measurement error of observed variables, and the residual of potential variables could all be obtained.

The initial model was constructed based on generally-known experience. After running in Amos, the chi-square $\left(\chi^{2}\right)$ test statistic value was 414.592 with $101 d f$, and a significant probability $(p)$ value of $0.0001(<0.05)$ in the model (Figure 1), which resulted in the rejection of the null hypothesis. The root meant square error of approximation (RMSEA) was 0.152 , under the null hypothesis of "close fit" (i.e., RMSEA is no greater than 0.05), as such, the adaptability of the hypothetical model to the observed data should be modified (Table 3).

Table 3. The fitting parameters describing the coupling relationship between stand structure and soil properties of artificial mixed forests in the Caijiachuan Watershed.

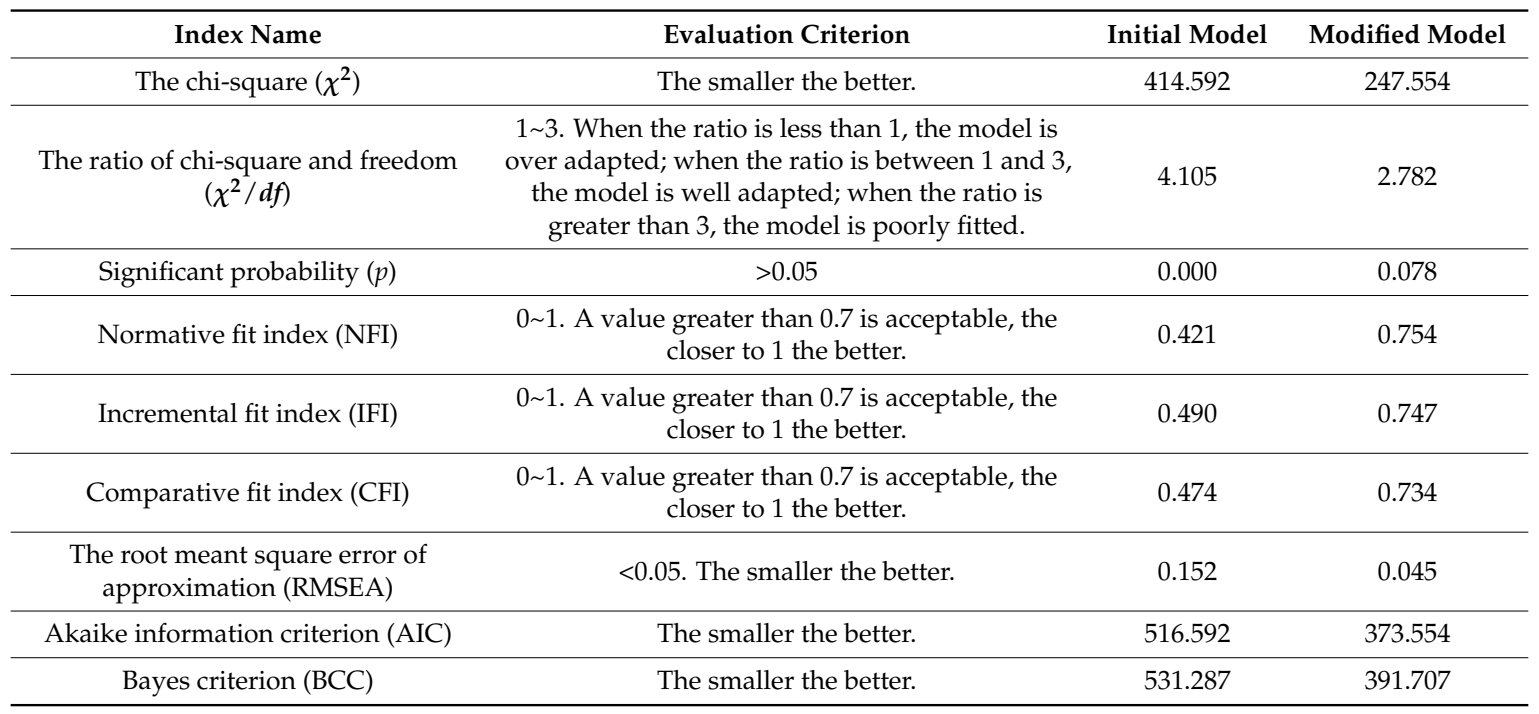




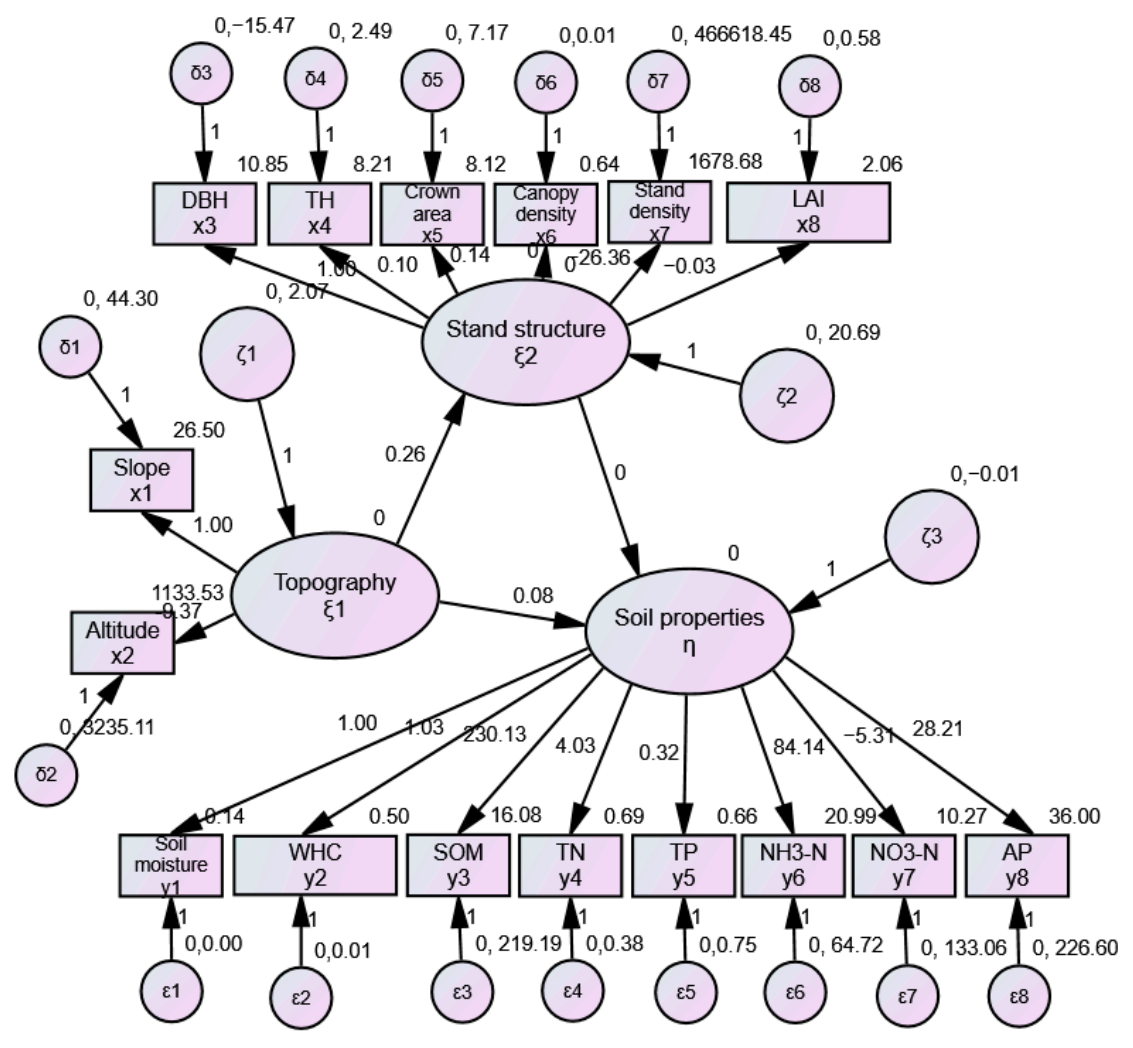

Figure 1. The initial structural equation model (SEM) used in the study. Note: The hypothesized initial model used for predicting topography, stand structure, and soil properties is based on soil and water conservation science. A rectangular box is used for each observed variable, with a measurement error, and the numbers correspond to the standardized path coefficients of the initial model on the single arrows in operation. A value outside of a rectangular box is the mean of the indicator, and a value outside of a round box is the residual error before modification. In the figure, DBH is the abbreviation for diameter at breast height; TH is the acronym for height of tree; LAI is the acronym for leaf area index; WHC is the abbreviation for soil maximum water holding capacity; SOM is the acronym for soil organic matter; TN is the is the acronym for total nitrogen; TP is the acronym for total phosphorus; $\mathrm{NH}_{3}-\mathrm{N}$ is the acronym for ammonia-nitrogen, $\mathrm{NO}_{3}-\mathrm{N}$ is the acronym for nitrate-nitrogen; and AP is the acronym for available phosphorus.

According to the current theoretical research and qualitative analyses of the conclusions, the model correction was completed using the "Modification Indices" hints of the Amos software. Principally, adding double arrows could express the correlation between the residuals of each variable, so that the parameters of the model were within an allowable range. After being modified, the chi-square $\left(\chi^{2}\right)$ test statistic value became 247.554 and the degree of freedom $(d f)$ reduced to 89 , with significant probability $(p)$ value of $0.078(>0.05)$ in the SEM (Figure 2$)$, which accepted the null hypothesis. The value of RMSEA was $0.045(<0.05)$, while normative fit index (NFI), incremental fit index (IFI), and CFI were each greater than 0.7 , inside the acceptable range, thus the model could be tolerated. Therefore, the test of the fittest indicators also met the standard, indicating that the fit of the model and the observed data were better after correction (Table 3). 


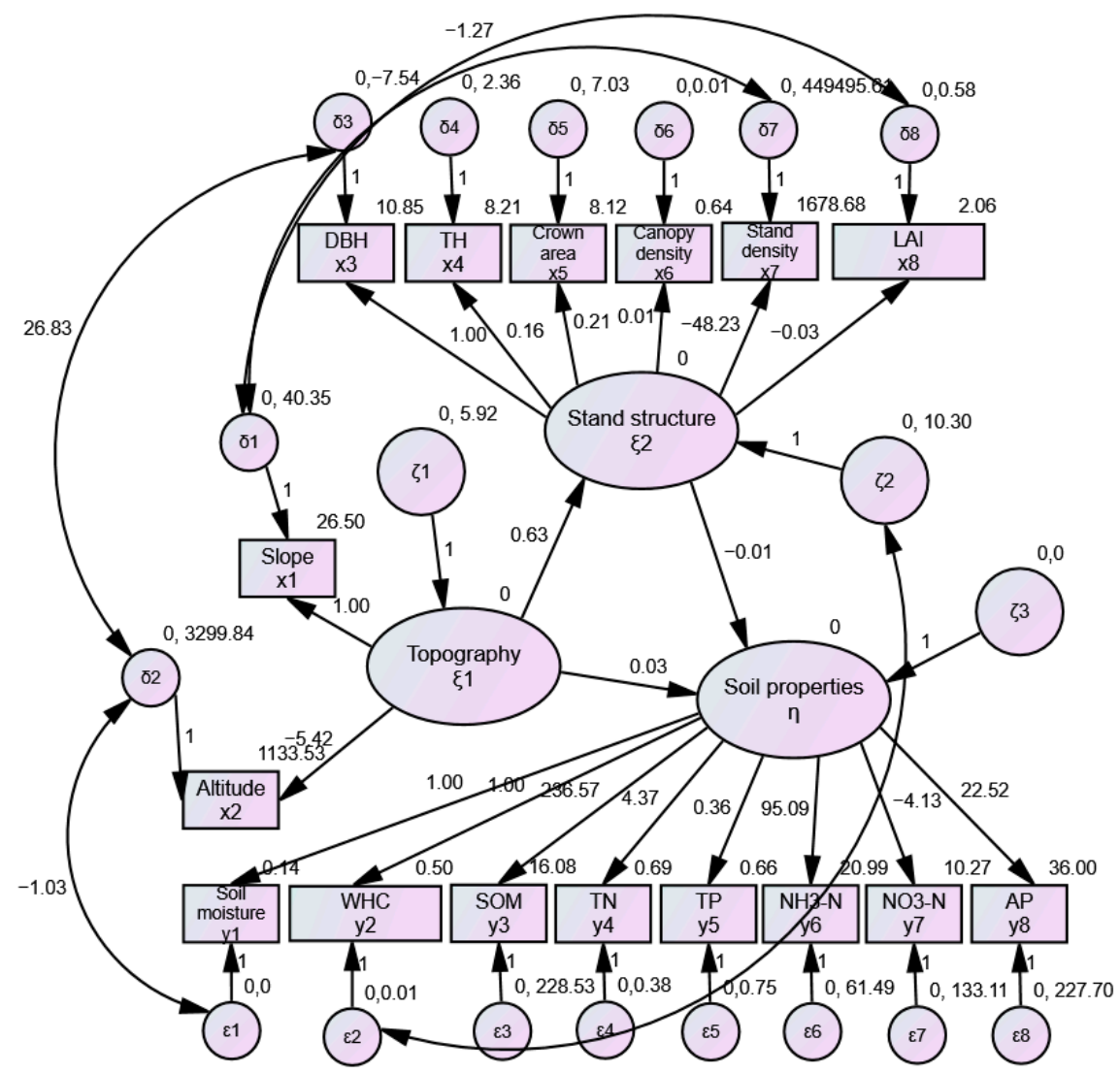

Figure 2. The modified model. Note: The numbers correspond to the standardized path coefficients on the single arrows, and to correlation coefficients on the double arrows. A value outside of a rectangular box is the mean of the indicator, and a value outside of a round box is the residual error after modification. In the figure, $\mathrm{DBH}$ is the abbreviation for diameter at breast height; $\mathrm{TH}$ is the acronym for height of tree; LAI is the acronym for leaf area index; WHC is the abbreviation for soil maximum water holding capacity; SOM is the acronym for soil organic matter; $\mathrm{TN}$ is the is the acronym for total nitrogen; $\mathrm{TP}$ is the acronym for total phosphorus; $\mathrm{NH}_{3}-\mathrm{N}$ is the acronym for ammonia-nitrogen, $\mathrm{NO}_{3}-\mathrm{N}$ is the acronym for nitrate-nitrogen; and AP is the acronym for available phosphorus.

\subsection{Model Explanation}

\subsubsection{Relationship between Latent Variables}

The topography had positive effects on the stand structure and soil characteristics (Figure 2), and the path coefficients were 0.63 and 0.03 , respectively. Numerically, the effect of topography on the stand structure was far greater than its impact on the soil. The stand structure had a negative impact on soil properties, with a path coefficient of -0.01 . Standardized influence coefficients characterized the effects of the latent variables, which were calculated using the SEM method (Table 4). The impact coefficient of topography on soil characteristics was 1.303, with a direct impact of 1.589 and an indirect impact of -0.285 ; the total impact and direct impact coefficients of stand structure on soil properties were both -0.585 ; and the total impact and direct impact coefficients of topography on stand structure were both 0.487 .

This showed that, after optimizing the stand structure, soil moisture and nutrients should be slightly influenced. In practice, the stand structure should be optimized as much as possible so as to increase the ecological function of stand. Simultaneously, the moderate stand structure adjustments should also be observed in order to avoid heavier constraints for the soil water resources and fertility when the negative impacts accumulate to a certain extent. 
Table 4. Standardized influence coefficients of latent variables in the structural equation model of Robinia pseudoacacia and Pinus tabulaeformis mixed plantations in the Caijiachuan Watershed.

\begin{tabular}{llll}
\hline \multirow{2}{*}{ Effect Type } & & Influences & \\
\cline { 3 - 4 } & & Topography & Stand Structure \\
\hline \multirow{2}{*}{ Standardized total impact } & Stand structure & 0.487 & \\
\multirow{2}{*}{ Standardized direct impact } & Soil characteristics & 1.303 & -0.585 \\
& Stand structure & 0.487 & \\
Standardized indirect impact & Soil characteristics & 1.589 & -0.585 \\
& Stand structure & & \\
& Soil characteristics & -0.285 & \\
\hline
\end{tabular}

\subsubsection{Relationship between Latent and Observed Variables}

The extent and effect of the influence between latent variables and observed variables were also reflected in the calculation of the path coefficient of the fit model (Figure 2). First, among the observed variables affecting the topographic factors, the slope showed a positive effect, but the altitude showed an opposite effect, which had a great influence on the topographic factors from a numerical point of view. Second, in the observed variables of influencing the stand structure, $\mathrm{DBH}, \mathrm{TH}$, crown width, and canopy density showed positive effects, whereas stand density and LAI both showed negative effects. The effect of stand density on the stand structure was much greater than the other factors. Third, among all of the observed variables that affected soil properties, all of them showed positive effects, except $\mathrm{NO}_{3}-\mathrm{N}$, and the order of their impacts on soil characteristics were: $\mathrm{SOM}>\mathrm{NH}_{3}-\mathrm{N}>\mathrm{AP}$ $>$ TN $>$ soil moisture $>$ WHC $>$ TP (Figure 2).

\section{Discussion}

The concept of SEM has been applied to many multivariable coupling studies in the natural sciences and has achieved good results in forest ecology studies. Application studies in forests [12,14,42,43], shrublands [13], wetlands [35], and other ecosystems [15] have proved the scientific basis and reliability of the model. Its importance is that it allows for the detection of topographic, stand structural, and soil characteristic factors that are responsible for structural and functional changes. However, the correct interpretation of these models requires a strong supply of ecological data and a good understanding of the characteristics of the topography-stand-soil system.

\subsection{Topography Mainly Impacted Stand Structure}

Topographical indicators commonly incorporate slope, aspect, altitude, slope length, and slope position, while the basal impacting factors of stand structure were $\mathrm{DBH}, \mathrm{TH}$, crown area, canopy density, stand density, forests diversity, LAI, and so on. Different topographic factors influenced forest diversity, structure, and dynamic change by their respective influencing mechanisms as supported by previous research that has demonstrated some aspects of these observations. For instance, tree height had a remarkable dissimilarity based on the slope and aspect of sites [44]; there was significant interaction between aspect and elevation in influencing forest structure [45]; and the vegetation should be adapted to various elevations according to relevant temperatures and other conditions [46].

Examining the data of the mixed plantation, a path coefficient of 0.63 illustrated that the effect of topography on the stand structure was the most important positive factor in the complex relationships. Standardized influence coefficients characterized the effects of the latent variables between topography and stand structure (Table 4). The total impact coefficient of the topography on the stand structure was 0.487 , all of which was attributed to direct impacts. Both of the results above demonstrated that if the conditions of the topography in an area became more advantageous, the stand structure can grow more favorably. 
In addition to representing the corresponding latent variables, observational variables indirectly affected other related latent variables and further revealed the indirect relationship between the latent variables [42]. The interactive relationship between the observed variables could preferably show the focus of the interaction among the systems represented by the latent variables and explain the current relationship of the latent variables more deeply. Observed variables such as DBH, TH, crown width, canopy density, stand density, and LAI, could not only characterize the stand structure, with the impact coefficients of $1.407,0.424,0.305,0.234,-0.243$, and -0.070 , but also relate to the topographical factors, with the impact coefficients reaching $0.686,0.277,0.144,0.114,-0.119$, and -0.034 (Table 5). As such, a deeper relationship between the indicators of the stand structure and the topographic factors could be clearly distinguished among them. The results showed that if the values of $\mathrm{DBH}, \mathrm{TH}$, crown area and canopy density were greater then the stand structure was more favorable; conversely, the direct influence of stand density and LAI on the stand structure was negative. Analogously, the indirect influence coefficients between the $\mathrm{DBH}, \mathrm{TH}$, crown area, canopy density, and topography were positive, but the others were negative.

\subsection{Topography Significantly Influenced Soil by Stand Structure Indirectly}

The soil characteristics studied in this paper were soil moisture content, WHC, SOM, TN, TP, $\mathrm{NH}_{3}-\mathrm{N}, \mathrm{NO}_{3}-\mathrm{N}$, and AP. The relation of one or several dimensions of these soil characteristics to topography have been found in past research. Slope has been shown to influence antecedent soil moisture which can potentially lead to either an increase or decrease in soil erosion, and is therefore a crucial consideration for recommending appropriate measures to protect soils [47]; there were some significant effects of altitudinal zone and slope aspect on the vertical distribution of soil organic carbon (close to SOM) density [48]. Topography usually has some form of direct impact on soil and, here, topography influenced soil indirectly via stand structure.

Topography had positive effects on the soil characteristics, with a path coefficient of 0.03 (Figure 2), which was a small absolute value. The most influential factor on soil characteristics was topography, with a total impact coefficient of 1.303; the direct impact being positive, and the indirect impact being negative (Table 4). This indicated that the majority of its impact on soil properties was through an indirect impact by influencing the stand structure. Through the stand structure adjustment, the topographic factors might change the formation of soil moisture and nutrients.

In addition to the representation of topography, the observed indicators, such as slope and elevation, were also related to soil characterization, and every factor of the soil characteristics had a positive impact on the topography, except for $\mathrm{NO}_{3}-\mathrm{N}$. The absolute value of the influence coefficient of soil water content on the topographical factors was 1.117, indicating that the impact of the factor on soil moisture was quite high. The values of TP and AP were only 0.052 and 0.043 , respectively, showing that the impact of phosphorus was weaker than the other factors' impacts on the topography. The results of this study align with other recent research that suggests that soil moisture content was the key factor for study site conditions and the status of stand structure. In the future, soil nutrient-related variables, such as organic matter, nitrogen, and phosphorus, should also be given special consideration. 
Table 5. Standardized influence coefficients between observed variables and latent variables in the structural equation model of Robinia pseudoacacia and Pinus tabulaeformis mixed plantations in the Caijiachuan Watershed.

\begin{tabular}{|c|c|c|c|c|c|c|c|c|c|}
\hline \multirow{3}{*}{ Observed Variables } & \multicolumn{9}{|l|}{ Influences } \\
\hline & \multicolumn{3}{|c|}{ Standardized Total Impact } & \multicolumn{3}{|c|}{ Standardized Direct Impact } & \multicolumn{3}{|c|}{ Standardized Indirect Impact } \\
\hline & Topography & $\begin{array}{l}\text { Stand } \\
\text { Structure }\end{array}$ & $\begin{array}{l}\text { Soil } \\
\text { Characteristics }\end{array}$ & Topography & $\begin{array}{l}\text { Stand } \\
\text { Structure }\end{array}$ & $\begin{array}{l}\text { Soil } \\
\text { Characteristics }\end{array}$ & Topography & $\begin{array}{l}\text { Stand } \\
\text { Structure }\end{array}$ & $\begin{array}{l}\text { Soil } \\
\text { Characteristics }\end{array}$ \\
\hline Slope & 0.342 & & & 0.342 & & & & & \\
\hline Altitude & -0.317 & & & -0.317 & & & & & \\
\hline $\mathrm{DBH}$ & 0.686 & 1.407 & & & 1.407 & & 0.686 & & \\
\hline Tree height & 0.207 & 0.424 & & & 0.424 & & 0.207 & & \\
\hline Canopy density & 0.114 & 0.234 & & & 0.234 & & 0.114 & & \\
\hline Stand density & -0.119 & -0.243 & & & -0.243 & & -0.119 & & \\
\hline LAI & -0.034 & -0.070 & & & -0.070 & & -0.034 & & \\
\hline Soil moisture content & 1.117 & -0.502 & 0.857 & & & 0.857 & 1.117 & -0.502 & \\
\hline WHC & 0.546 & -0.245 & 0.419 & & & 0.419 & 0.546 & -0.245 & \\
\hline SOM & 0.732 & -0.329 & 0.561 & & & 0.561 & 0.732 & -0.329 & \\
\hline $\mathrm{TN}$ & 0.306 & -0.138 & 0.235 & & & 0.235 & 0.306 & -0.138 & \\
\hline $\mathrm{TP}$ & 0.052 & -0.023 & 0.040 & & & 0.040 & 0.052 & -0.023 & \\
\hline $\mathrm{NH}_{3}-\mathrm{N}$ & 0.547 & -0.245 & 0.419 & & & 0.419 & 0.547 & -0.245 & \\
\hline
\end{tabular}

Note: In the table, DBH is the abbreviation for diameter at breast height; LAI is the acronym for leaf area index; WHC is the abbreviation for soil maximum water holding capacity; SOM is the acronym for soil organic matter; $\mathrm{TN}$ is the is the acronym for total nitrogen; $\mathrm{TP}$ is the acronym for total phosphorus; $\mathrm{NH}_{3}-\mathrm{N}$ is the acronym for ammonia-nitrogen, $\mathrm{NO}_{3}-\mathrm{N}$ is the acronym for nitrate-nitrogen; and AP is the acronym for available phosphorus. 


\subsection{Stand Structure Impacted Soil Properties to a Comparatively Smaller Degree}

The relationships of the stand structure and soil properties were the essential issues. There have been many studies on these factors in the field of ecological systems and soil and water conservation. Soil variables have been observed to differ in terms of soil TN across the different canopy types [49]. Forest structure has effects on microbiological soil properties and nutrient content [50]; however, a great many of these effects still remain in the realm of single-factor impact research. Additionally, using the SEM method to explore the multi-factors, we found that the stand structure impacted soil properties with a path coefficient of -0.01 . The total impact coefficient of stand structure on soil properties was -0.585 , all of which was attributed to direct impacts. The results indicated that, under the suitable conditions of topographic factors, the stand might negatively impact soil moisture and nutrient conditions.

The effects of the observed variables on latent variables are also described in Table 5. Soil moisture content, $\mathrm{WHC}, \mathrm{SOM}, \mathrm{TN}, \mathrm{TP}, \mathrm{NH}_{3}-\mathrm{N}, \mathrm{NO}_{3}-\mathrm{N}$, and $\mathrm{AP}$ were related to stand structure, apart from the representation of soil characterization. Here, stand structure had a positive relationship to $\mathrm{NO}_{3}-\mathrm{N}$, but it had negative influence coefficients with all of the other soil factors, along with a small absolute value. Soil moisture content was most sensitive, with an influence coefficient of -0.502 on the stand structure. Adversely, the values of TP and AP were -0.023 and -0.019 , demonstrating that phosphorus was weakly influenced by the stand structure. These results verify that the benefits of studying stand and soil moisture in an arid area are great, and that the soil nutrients also play a significant and crucial role in forest stand research.

\section{Conclusions}

The soil characteristics of R. pseudoacacia and P. tabulaeformis mixed plantations in the Caijiachuan Watershed were mainly limited by factors such as the regional topography and the stand structure; SEM satisfactorily quantified the relationships between these factors. The modeling indicated that if the topography was more suitable and the stand structure was more favorable then soil moisture and fertility conditions would be better. This finding was consistent with the initial empirical assumption $[1-7,47,50]$, with the results of this study offering a more statistically accurate expression than previously determined. The stand structure had little effect on soil properties, all of which were negatively and directly affected, indicating that it imposed certain restrictions on the retained moisture and nutrients in the soil. Observed variables also correlated well with the latent variables. The mutual indirect influences between the observed variables and the two latent variables of topography and stand structure were comparatively high.

Based on all the above, the quantification process should provide new insights into the management and conservation of forests. In line with the quantified effective values of impact between these interrelated factors, some measures may in fact adjust terrain and stand structure to effectively maintain or increase the soil moisture and nutrient content in reality, such as changing the gradient of micro-topography, or reducing the stand density. These measures could enhance the functions of soil and water conservation. In the Loess Plateau, the conservation and forestry staff can achieve this positive outcome by excavating level steps and fish-scale pits to lessen the slopes or reduce runoff, or by artificial tree-tending in order to change the stand structure according to the path coefficient of the modified model. The results can serve as a reference for determining care and management measures suitable for the R. pseudoacacia and P. tabulaeformis plantations, as well as for controlling the stand structure on the Loess Plateau and improving the region's soil and water conservation functions.

Acknowledgments: This study was supported by grants from the National Key R \& D Program of China (No. 2016YFC0501704), the Natural Science Fund (31500523), the Fund for Introduced Talents for Shanxi Agricultural University (2014YJ19), and the Beijing Municipal Education Commission Beijing Collaborative Innovation Center for Eco-Environmental Improvement with Forestry and Fruit Trees (PXM2017_014207_000024). We would like to thank our colleagues for their comments on this paper before submission. 
Author Contributions: H.B. and X.W. designed the experiments. X.W. and W.L. wrote the paper and reviewed the manuscript. All authors conducted the experiments.

Conflicts of Interest: The authors declare no conflict of interest.

\section{References}

1. Bi, H.X.; Li, X.Y.; Li, J.; Guo, M.X.; Liu, X. Study on suitable vegetation cover on Loess area based on soil water balance. Sci. Silvae Sin. 2007, 43, 17-24.

2. Brzostek, E.R.; Dragoni, D.; Schmid, H.P.; Rahman, A.F.; Sims, D.; Wayson, C.A.; Johnson, D.J.; Phillips, R.P. Chronic water stress reduces tree growth and the carbon sink of deciduous hardwood forests. Glob. Chang. Biol. 2014, 28, 2531-2539. [CrossRef] [PubMed]

3. Panagos, P.; Borrelli, P.; Poesen, J.; Ballabio, C.; Lugato, E.; Meusburger, K.; Montanarella, K.; Alewell, C. The new assessment of soil loss by water erosion in Europe. Environ. Sci. Policy 2015, 54, 438-447. [CrossRef]

4. Li, S.; Liang, W.; Fu, B.J.; Lv, Y.H.; Fu, S.Y.; Wang, S.; Su, H.M. Vegetation changes in recent large-scale ecological restoration projects and subsequent impact on water resources in China's Loess Plateau. Sci. Total Environ. 2016, 569, 1032-1039. [CrossRef] [PubMed]

5. Zhang, X.; Zhao, W.W.; Liu, Y.X.; Fang, X.N.; Feng, Q. The relationships between grasslands and soil moisture on the Loess Plateau of China: A review. Catena 2016, 145, 56-67. [CrossRef]

6. Shi, W.Y.; Du, S.; Joseph, C.M.; Guan, J.H.; Wang, K.B.; Ma, M.G.; Norikazu, Y.; Ryunosuke, T. Physical and biogeochemical controls on soil respiration along a topographical gradient in a semiarid forest. Agric. For. Meteorol. 2017, 247, 1-11. [CrossRef]

7. Wang, Y.H.; Yu, P.T.; Wang, J.Z.; Xu, L.H.; Karl, H.F.; Xiong, W. Multifunctional forestry on the Loess Plateau. Earth Environ. Sci. 2017, 4, 79-107.

8. Zhang, C.; Wang, Z.G.; Ling, F.; Ji, Q.; Meng, F.B. Function evaluation of soil and water conservation and its application in soil and water conservation regionalization. Sci. Soil Water Conserv. 2016, 14, 90-99.

9. Pimentel, D.; Harvey, C.; Resosudarmo, P.; Sinclair, K.; Kurz, D.; McNair, M.; Crist, S.; Shpritz, L.; Fitton, L.; Saffouri, R.; et al. Environmental and Economic Costs of Soil Erosion and Conservation Benefits. Science 1995, 267, 1117-1123. [CrossRef] [PubMed]

10. Grace, J.B. The factors controlling species density in herbaceous plant communities: An assessment. Perspect. Plant Ecol. Evol. Syst. 1999, 2, 1-28. [CrossRef]

11. Grace, J.B.; Anderson, T.M.; Smith, M.D.; Seabloom, E.; Andelman, S.J.; Meche, G.; Weiher, E.; Allain, L.K.; Jutila, H.; Sankaran, M.; et al. Does species diversity limit productivity in natural grassland communities? Ecol. Lett. 2007, 10, 680-689. [CrossRef] [PubMed]

12. Miao, S.L.; Carstenn, S.; Nungesser, M. Real World Ecology: Large-Scale and Long-Term Case Studies and Methods; Springer: New York, NY, USA, 2009.

13. Wang, S.L.; Liang, X.J.; Ma, C.; Zhou, J.P. Coupling relationship between Hedysarum mongdicum shrub plantation and sand soil based on structural equation model. J. Beijing For. Univ. 2017, 39, 1-8.

14. Grace, J.B.; Anderson, T.M.; Olff, H.; Scheiner, S.M. On the specification of structural equation models for ecological systems. Ecol. Monogr. 2010, 80, 67-87. [CrossRef]

15. Erin, M.M.; Samiran, B.; Edward, W.B.; Linda, M.H.; Donald, D.H. Structural equation modeling reveals complex relationships in mixed forage swards. Crop Prot. 2015, 78, 106-113.

16. Shipley, B. Cause and Correlation in Biology; Cambridge University Press: Cambridge, UK, 2000.

17. Jonsson, M.; Wardle, D.A. Structural equation modelling reveals plantcommunity drivers of carbon storage in boreal forest ecosystems. Biol. Lett. 2010, 6, 116-119. [CrossRef] [PubMed]

18. Lamb, E.G.; Kennedy, N.; Siciliano, S.D. Effects of plant species richness and evenness on soil microbial community diversity and function. Plant Soil 2011, 338, 483-495. [CrossRef]

19. Lamb, E.; Shirtliffe, S.; May, W. Structural equation modelling in the plant sciences: An example using yield components in oat. Can. J. Plant Sci. 2011, 91, 603-619. [CrossRef]

20. Laliberté, E.; Tylianakis, J.M. Cascading effects of long-term land-use changes on plant traits and ecosystem functioning. Ecology 2012, 93, 145-155. [CrossRef] [PubMed]

21. Chen, D.; Zheng, S.; Shan, Y.; Taube, F.; Bai, Y. Vertebrate herbivore-induced changes in plants and soils: Linkages to ecosystem functioning in a semi-arid steppe. Funct. Ecol. 2013, 27, 273-281. [CrossRef] 
22. Diouf, A.; Barbier, N.; Lykke, A.M.; Couteron, P.; Deblauwe, V.; Mahamane, A.; Bogaert, J. Relationships between fire history, edaphic factors andwoody vegetation structure and composition in a semi-arid savanna landscape (Niger, West Africa). Appl. Veg. Sci. 2012, 15, 488-500. [CrossRef]

23. Matías, L.; Castro, J.; Zamora, R. Effect of simulated climate change on soil respiration in a Mediterranean-type ecosystem: Rainfall and habitat type are more important than temperature or the soil carbon pool. Ecosystems 2012, 15, 299-310. [CrossRef]

24. Riseng, C.M.; Wiley, M.J.; Black, R.W.; Munn, M.D. Impacts of agricultural land use on biological integrity: A causal analysis. Ecol. Appl. 2011, 21, 3128-3146. [CrossRef]

25. Leithead, M.; Anand, M.; Duarte, L.D.S.; Pillar, V.D. Causal effects of latitude, disturbance and dispersal limitation on richness in a recovering temperate, subtropical and tropical forest. J. Veg. Sci. 2012, 23, 339-351. [CrossRef]

26. Virginia, C.; Madhur, A. Assessing ecological integrity: A multi-scale structural and functional approach using Structural Equation Modeling. Ecol. Indic. 2016, 71, 258-269.

27. Desrochers, R.E.; Kerr, J.T.; Currie, D.J. How, and how much, natural cover loss increases species richness. Glob. Ecol. Biogeogr. 2011, 20, 857-867. [CrossRef]

28. Gazol, A.; Tamme, R.; Takkis, K.; Kasari, L.; Saar, L.; Helm, A.; Pärtel, M. Landscape- and small-scale determinants of grassland species diversity: Directand indirect influences. Ecography 2012, 35, 944-951. [CrossRef]

29. Santibáñez-Andrade, G.; Castillo-Argüero, S.; Vega-Peña, E.V.; Lindig-Cisnerosc, R.; Zavala-Hurtado, J.A. Structural equation modeling as a tool to develop conservation strategies using environmental indicators: The case of the forests of the Magdalena river basin in Mexico City. Ecol. Indic. 2015, 54, 124-136. [CrossRef]

30. Xu, Z. Study on Ecological Function Evaluation and Biodiversity of Typical Forest Stands in Jinxi of the Loess Plateau. Master's Thesis, Beijing Forestry University, Beijing, China, 2014.

31. Quinn, G.P.; Keough, M.J. Experimental Design and Data Analysis for Biologists; Cambridge University Press: New York, NY, USA, 2002.

32. Ruiz, M.A.; Pardo, A.; San Martín, R. Structural equation models. Psychol. Roles 2010, 31, $34-45$.

33. Schumacker, R.E.; Lomax, R.G. A Beginner's Guide to Structural Equation Modeling; Taylor and Francis Group, LLC: Mahwah, NJ, USA, 2004.

34. Valdés, A.; García, D. Direct and indirect effects of landscape change on the reproduction of a temperate perennial herb. J. Appl. Ecol. 2011, 48, 1422-1431. [CrossRef]

35. Sutton-Grier, A.E.; Kenney, M.A.; Richardson, C.J. Examining the relationship between ecosystem structure and function using structural equation modelling: A case study examining denitrification potential in restored wetland soils. Ecol. Model. 2010, 221, 761-768. [CrossRef]

36. McCune, B.; Grace, J.B. Analysis of Ecological Communities; MjM Software Design: Gleneden Beach, OR, USA, 2002.

37. Bollen, K.A. Structural Equations with Latent Variables; John Wiley \& Sons: New York, NY, USA, 1989.

38. Joreskog, K.G.; Sorbom, D. LISREL 8 User's Reference Guide; Scientific Software International: Chicago, IL, USA, 1993.

39. Hau, K.T.; Cheng, Z.J. Application and analytical strategies of structural equation modeling. Explor. Psychol. 1999, 19, 54-59.

40. Schermelleh, K.; Moosbrugger, H. Evaluating the fit of structural equation models: Tests of significance and descriptive goodness-of-fit measures. Methods Psychol. Res. 2003, 8, 23-74.

41. Wu, M.L. Structural Equation Model-The Operation and Application of AMOS; Chongqing University Press: Chongqing, China, 2010.

42. Li, H.; Wang, J.K.; Pei, J.B.; Li, S.Y. Equilibrium relationships of soil organic carbon in the main croplands of northeast China based on structural equation modeling. Acta Ecol. Sin. 2015, 35, 517-525. [CrossRef]

43. Brahim, N.; Blavet, D.; Gallali, T.; Bernoux, M. Application of structural equation modeling for assessing relationships between organic carbon and soil properties in semiarid Mediterranean region. Int. J. Environ. Sci. Technol. 2011, 8, 305-320. [CrossRef]

44. Hanieh, S.; Lalit, K.; Russell, T.; Christine, S. Airborne LiDAR derived canopy height model reveals a significant difference in radiata pine (Pinus radiata D. Don) heights based on slope and aspect of sites. Trees 2014, 28, 733-744. 
45. Eshetu, Y.; Mike, S.; Mesele, N.; Fantaw, Y. Influence of topographic aspect on floristic diversity, structure and treeline of afromontane cloud forests in the Bale Mountains, Ethiopia. J. For. Res. 2015, 26, 919-931.

46. Koichi, T.; Satomi, M. Morphological variations of the Solidago virgaurea L. complex along an elevational gradient on Mt Norikura, central Japan. Plant Species Biol. 2017, 32, 238-246.

47. Ziadat, F.M.; Taimeh, A.Y. Effect of rainfall intensity, slope, land use and antecedent soil moisture on soil erosion in an arid environment. Land Degrad. Dev. 2013, 24, 582-590. [CrossRef]

48. Tshering, D.; Inakwu, O.A.O.; Damien, J.F. Vertical distribution of soil organic carbon density in relation to land use/cover, altitude and slope aspect in the eastern Himalayas. Land 2014, 3, 1232-1250.

49. Ou, Z.Y.; Cao, J.Z.; Shen, W.H.; Tan, Y.B.; He, Q.F.; Peng, Y.H. Understory flora in relation to canopy structure, soil nutrients, and gap light regime: A case study in southern China. Pol. J. Environ. Stud. 2015, 24, 2559-2568. [CrossRef]

50. Lucas-Borja, M.E.; Hedo, J.; Cerdá, A.; Candel-Pérez, D.; Viñegla, B. Unravelling the importance of forest age stand and forest structure driving microbiological soil properties, enzymatic activities and soil nutrients content in Mediterranean Spanish black pine (Pinus nigra Ar. ssp. salzmannii) Forest. Sci. Total Environ. 2016, 562, 145-154. [CrossRef] [PubMed]

(C) 2018 by the authors. Licensee MDPI, Basel, Switzerland. This article is an open access article distributed under the terms and conditions of the Creative Commons Attribution (CC BY) license (http://creativecommons.org/licenses/by/4.0/). 